OPEN ACCESS

Edited by: Cendrine Mony, University of Rennes 1, France

Reviewed by:

Jincai Ma,

Jilin University, China

Claudia Coleine,

University of Tuscia, Italy

*Correspondence:

Qiang Li

glqiangli@hotmail.com

Specialty section:

This article was submitted to Terrestrial Microbiology, a section of the journal

Frontiers in Microbiology

Received: 01 December 2020

Accepted: 15 February 2021

Published: 10 March 2021

Citation:

$L i Q$, Song $A$, Yang $H$ and Müller WEG (2021) Impact of Rocky

Desertification Control on Soil Bacterial Community in Karst Graben

Basin, Southwestern China.

Front. Microbiol. 12:636405

doi: 10.3389/fmicb.2021.636405

\section{Impact of Rocky Desertification Control on Soil Bacterial Community in Karst Graben Basin, Southwestern China}

\author{
Qiang $\mathrm{Li}^{1,2 *}$, Ang Song ${ }^{1,2}$, Hui Yang ${ }^{1,2}$ and Werner E. G. Müller ${ }^{3}$ \\ ${ }^{1}$ Key Laboratory of Karst Dynamics, MNR and GZAR, Institute of Karst Geology, Chinese Academy of Geological Sciences, \\ Guilin, China, ${ }^{2}$ International Research Center on Karst Under the Auspices of UNESCO, Guilin, China, ${ }^{3}$ ERC Advanced \\ Investigator Grant Research Group, Institute for Physiological Chemistry, University Medical Center of the Johannes \\ Gutenberg University Mainz, Mainz, Germany
}

Microorganisms play critical roles in belowground ecosystems, and karst rocky desertification (KRD) control affects edaphic properties and vegetation coverage. However, the relationship between KRD control and soil bacterial communities remains unclear. 16S rRNA gene next-generation sequencing was used to investigate soil bacterial community structure, composition, diversity, and co-occurrence network from five ecological types in KRD control area. Moreover, soil physical-chemical properties and soil stoichiometry characteristics of carbon, nitrogen and phosphorus were analyzed. Soil $\mathrm{N}$ and $\mathrm{P}$ co-limitation decreased in the contribution of the promotion of KRD control on edaphic properties. Though soil bacterial communities appeared strongly associated with soil $\mathrm{pH}$, soil calcium, soil phosphorus and plant richness, the key factor to determine their compositions was the latter via changed edaphic properties. The co-occurrence network analysis indicated that soil bacterial network complexity in natural ecosystem was higher than that in additional management ecosystem. Candidatus Udaeobacter, Chthoniobacterales, and Pedosphaeraceae were recognized as the key taxa maintaining karst soil ecosystems in KRD control area. Our results indicate that natural recovery is the suitable way for restoration and rehabilitation of degraded ecosystems, and thus contribute to the ongoing endeavor to appraise the interactions among soil-plant ecological networks.

Keywords: ecological type, $16 \mathrm{~S}$ amplicon sequencing, co-occurrence network, karst rocky desertification control, karst graben basin

\section{HIGHLIGHTS}

- Returning farmland to forests in karst graben basin enhances soil prosperity.

- Plant species richness shapes soil bacterial communities via the changed edaphic properties.

- Soil Candidatus Udaeobacter, Chthoniobacterales, and Pedosphaeraceae play key roles in biogeochemical cycles of organic materials.

- Soil bacterial network complexity in natural ecosystem is higher than that in additional management ecosystem.

- Natural recovery is the suitable way for restoration and rehabilitation of degraded ecosystems. 


\section{INTRODUCTION}

Karst environment is fragile in southwest China due to the particularities of soluble carbonate rock, rich calcium, soil scarcity and water leakage, etc (Yuan, 2001). Under the pressure of 1.7 million people living there, forest, especially at the slope $>25^{\circ}$ area, was destroyed for agriculture; consequently, an ecological disaster, named karst rocky desertification (KRD), relating to deforestation and soil loss, was formed (Yuan, 1997; Jiang et al., 2014). KRD control project (returning farmland to forests) was applied to recover the disturbed karst ecosystem in southwestern China, which may affect soil physical, chemical and biological properties (Jiang et al., 2014; Li et al., 2014; Chang et al., 2018; Bai et al., 2019) and vegetation coverage (Jiang et al., 2014; Tong et al., 2018).

Microorganisms are important components of soils (Beveridge, 1989), which play major roles in maintaining biogeochemical cycling, complexity and stability of belowground ecosystems (Delgado-Baquerizo et al., 2018, 2019; Wagg et al., 2019). Predictive understanding of soil bacterial communities is very important to forecast the ecological consequences caused by environmental changes (Delgado-Baquerizo et al., 2018; Liang et al., 2020). Besides, the advent of high-throughput sequencing technologies provide a rapid and low-cost tool to understand microbial ecology, such as microbial community structures, diversities, interactions and co-occurrence patterns (Loman et al., 2012; Ma et al., 2016; Xue et al., 2017, 2020; Schmidt et al., 2019; Wagg et al., 2019).

Previous researches also have shown that soil bacterial communities can be shaped by edaphic properties such as pH, Ca (Paul, 2007; Xue et al., 2017; Delgado-Baquerizo et al., 2018, 2019; Li et al., 2021) and plant factors such as species structure and diversity (Marschner et al., 2001; Van der Heijden et al., 2008; Lamb et al., 2011; Lange et al., 2014; Dassen et al., 2017; Ma et al., 2019; Zhong et al., 2020). However, the characterizing changes in soil bacterial community structure and diversity in response to KRD control remains still unclear. This is unsurprising given that soil, the continuous spatio-temporal heterogeneity with high spatial variability, harbors vast soil microorganisms (Yuan, 1997; Harris, 2009; Jiang et al., 2014; Delgado-Baquerizo et al., 2018, 2019), and natural and artificial ecosystems after returning farmland to forests are different (Swenson et al., 2000). Put simply, some bacteria are highly abundant under particular environmental conditions (Ma et al., 2016; Delgado-Baquerizo et al., 2018). For these reasons, we lack systematic understanding of the interactions among KRD control and soil bacterial communities in a given karst area.

To reduce the knowledge gap, the "space-for-time substitution" approach (Pickett, 1989) and high-throughput sequencing of the 16S rRNA gene were applied to explore the characterizing changes of soil bacterial community structure and diversity, and their responses to returning farmland to forests from KRD control area in Hani-Yi Autonomous Prefecture of Honghe, Yunnan Province, China. Though "space-for-time substitution" approach has shortcomings, it is still recognized as the only way of determining long-term ecological dynamics
(Wogan and Wang, 2018). Then, the starting point of this study is the question whether the soil bacterial community difference exists among different ecology types along the successional gradients in KRD control area. Another question is: if the difference exists, do you provide any evidence to determine the soil eco-stability with ecological type? Finally, we want to reveal the determining factor(s) shaping soil bacterial communities in our study.

\section{MATERIALS AND METHODS}

\section{Study Area}

Hani-Yi Autonomous Prefecture of Honghe $\left(101^{\circ} 47^{\prime}-104^{\circ} 16^{\prime} \mathrm{E}\right.$, $22^{\circ} 26^{\prime}-24^{\circ} 45 \mathrm{~N}$ ) is located at the juncture of the Tethys and Pacific tectonic domain, resulting in the formation of sedimentary basins of graben type over the Yunnan Plateau (Qin et al., 1996; Duan et al., 2005; Li et al., 2021). Nearly 55\% of this autonomous prefecture of $33430 \mathrm{~km}^{2}$ is karstic. The KRD area covered $2345.08 \mathrm{~km}^{2}$ in 2016 (Zhao et al., 2019). Karst soil layers are usually $20-40 \mathrm{~cm}$ thick. About $80 \%$ of annual rainfall $(2026.5 \mathrm{~mm})$ concentrates in the rainy season onset of May but end of the October (Duan et al., 2005), which falls within the subtropics with two distinctive seasons (dry and wet seasons). The average annual temperature is $16.3^{\circ} \mathrm{C}$.

\section{Bulk Soil Sampling}

Nineteen plots with the size of approximately $10 \times 10 \mathrm{~m}^{2}$ were randomly selected for bulk calcareous soil sampling in Oct, 2016. In the total 19 plots (Figure 1), there are six plots from corn land (CL) with Zea mays, four plots from grassland (GL) covered mainly by Arundinella setosa, three plots from natural restoration forest with Alnus ferdinandicoburgii Schneid (AF), three plots from artificial restoration forest with Pinus yunnanensis forest (PF) and three plots from rock covered soil without disturbance (RD) covered mainly by Bauhinia brachycarpa, Cymbopogon distans and Cyclobalanopsis glaucoides Schottky. Each ecological plot has been used for more than 10 years. $264: 75: 13.5 \mathrm{~kg} \mathrm{~N}: \mathrm{P}_{2} \mathrm{O}_{5}: \mathrm{K}_{2} \mathrm{O} / \mathrm{hm}^{2}$ and $15,000 \mathrm{~kg}$ organic fertilizer $/ \mathrm{hm}^{2}$ were applied on the CL soil every year, and GL, AF as well as PF recovery from CL were under natural restoration without human intervention. Considering the heterogeneity of sampling plots, plant biodiversity was investigated in term of Gleason index (the average plant Gleason index in $\mathrm{CL}, \mathrm{GL}, \mathrm{AF}, \mathrm{PF}$, and $\mathrm{RD}$ were 2.8, 7.7, 7.3, 5.4, and 9.6, respectively). When bulk soils were sampling, the sampling plots were uniformly distributed along an S-type, and every three diagonal sampling cores with $5 \mathrm{~cm}$ diameter and $10 \mathrm{~cm}$ depth in each plot were combined to obtain a composite soil sample. After stones, plant as well as root debris removed, the 19 soil samples in total were used for downstream analysis.

\section{Analysis of Bulk Soil Properties}

Soil pH, soil organic carbon (SOC), total nitrogen (TN) and total phosphorus (TP) were analyzed by using the air-dried and sieved (0.2 mm) soil samples (Li et al., 2015a). The exchangeable bases 


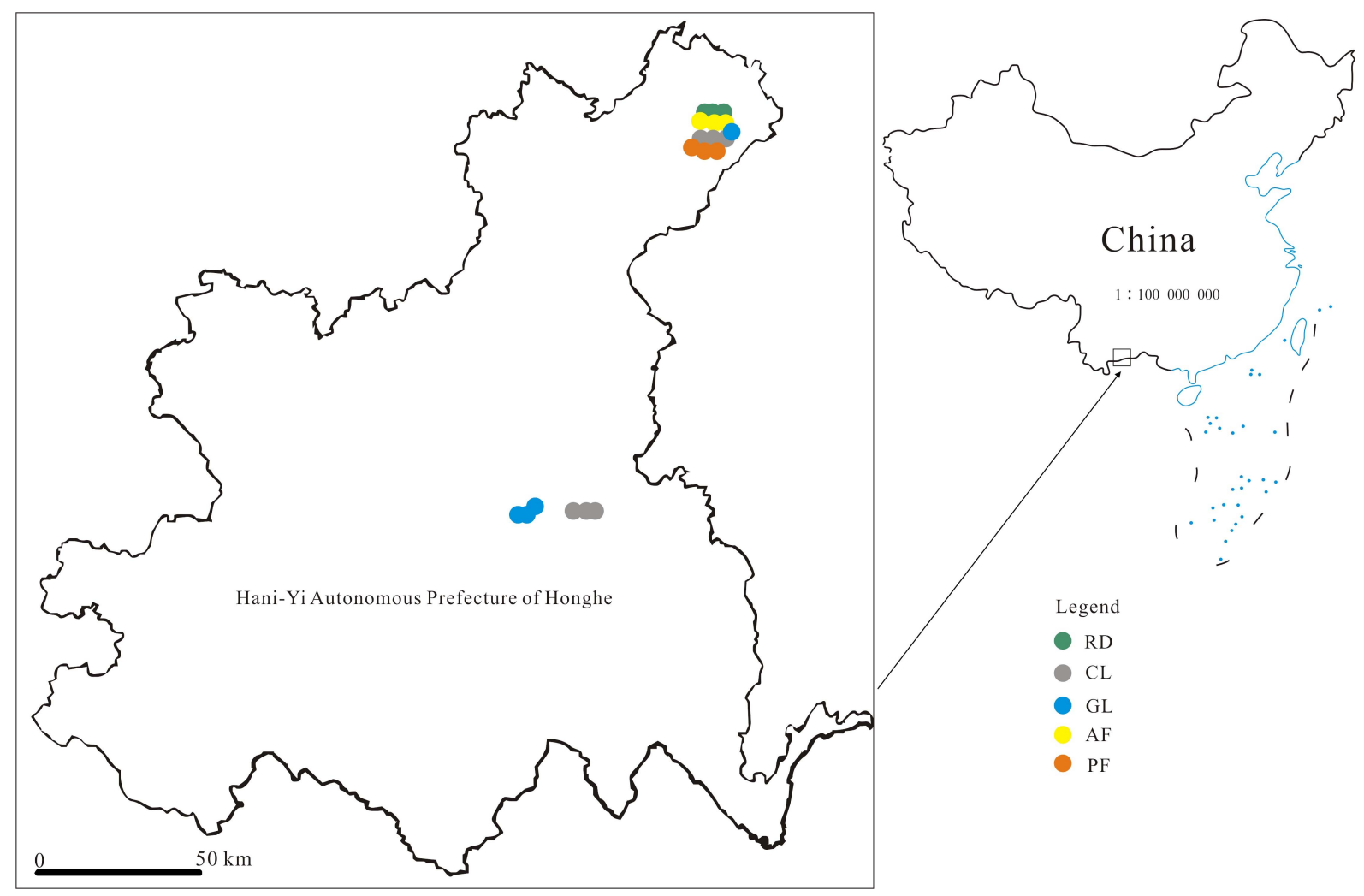

FIGURE 1 | Map showing localization of the bulk soil samples in Hani-Yi Autonomous Prefecture of Honghe, China. Figure 1 was generated by QGIS that is a free and open source geographic information system (https://www.qgis.org/en/site/).

TABLE 1 | Mean soil properties in five ecological types.

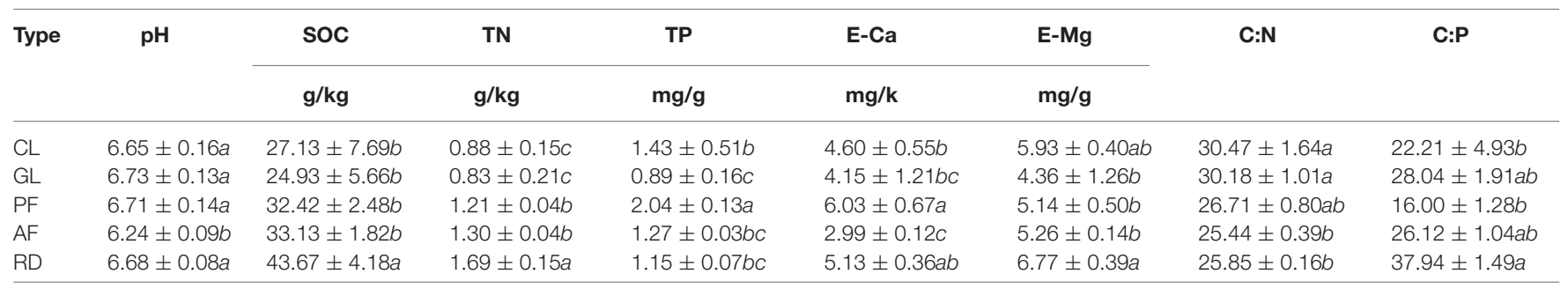

Values are the mean of analytical replicates for each sample \pm standard deviations. Statistical pairwise multiple comparisons of data homogeneity were carried out by the LSD test: means with the same letter in the same column are not significantly different at $P<0.05$.

calcium (E-Ca) and magnesium (E-Mg) were extracted using an ion-exchange resin (McKinley et al., 2007). The soil properties are summarized in Table $\mathbf{1 .}$

\section{High-Throughput Sequencing and Bioinformatic Analysis}

Soil DNA was extracted from $0.25 \mathrm{~g}$ fresh soil by using PowerSoil DNA Isolation Kit (Mobio Laboratories, Inc., Carlsbad, CA, United States) in strict accordance with the manufacturer's instructions.

PCR primers 515F (5'-GTGCCAGCMGCCGCGGTAA-3') and 907R (5'-CCGTCAATTCMTTTRAG TTT- $\left.3^{\prime}\right)$ with a 12-bp barcode sequence at the $3^{\prime}$ end were used for amplification of the
V4-V5 region of 16S rRNA genes (Tamaki et al., 2011). The PCR amplification $(60 \mu \mathrm{l})$ were done in $6 \mu \mathrm{l} 10 \times \mathrm{Ex}$ Taq buffer, $6 \mu \mathrm{l}$ dNTP mixture, $0.6 \mu \mathrm{l}$ BSA, $0.3 \mu \mathrm{l}$ Ex Taq, $1.2 \mu \mathrm{l}$ of each primer, $1 \mu \mathrm{l}$ DNA template, $43.7 \mu \mathrm{l}$ sterile deionized water (Guangzhou MAGIENE Biotech Co., Ltd., China). PCR conditions were $5 \mathrm{~min}$ at $94^{\circ} \mathrm{C}$ followed by 31 cycles of $30 \mathrm{~s}$ at $94^{\circ} \mathrm{C}, 30 \mathrm{~s}$ at $52^{\circ} \mathrm{C}$ and $45 \mathrm{~s}$ at $72^{\circ} \mathrm{C}$ followed by a final extension for $10 \mathrm{~min}$ at $72^{\circ} \mathrm{C}$. After the PCR amplification, samples were held at $16^{\circ} \mathrm{C}$ for $10 \mathrm{~min}$ and then were analyzed on $1 \%$ agarose gel. High quality PCR products were purified by using the TIANquick Maxi Purification Kit [TIANGEN Biotech (Beijing) Co., Ltd., China] and sequencing was performed on the Illumina HiSeq 2500 platform (Illumina Inc., San Diego, CA, United States) to generate $250 \mathrm{bp}$ paired-end reads in the company of MAGIENE 
(Guangzhou, China). The achieved raw sequence reads were submitted to the NCBI Sequence Read Archive under the accession numbers PRJNA471031 and PRJNA471162.

Raw sequencing reads were processed by QIIME version 1.9.1. Sequences with low quality (length $<300$ bp or average base quality score $<20$ ) were removed. Chimeric reads were identified and excluded through the Usearch (version 5.2.236). Moreover, reads which were not classified into bacteria and annotated as chloroplast and mitochondria were discarded. Then, 1481930 raw reads, with a minimum sequencing depth of 60317 reads per sample, resulted in 1426986 high-quality sequences. The clean reads were grouped into operational taxonomic units (OTUs) based on a genetic similarity of $97 \%$ by using Usearch version 5.2.236. To ensure that well-characterized strains were included in the phylogenetic analysis, the 16S rRNA gene sequences of type strains from each of the target taxa were extracted from the Silva version $13216 \mathrm{~S}$ rRNA database. In this study, soil bacterial communities are focused; consequently the detailed data of $16 \mathrm{~S}$ rRNA gene sequencing except for archaea are summarized in Supplementary Table 1.

\section{Data Analysis}

In our study, the C:N and C:P ratios were calculated based on the ratios between concentrations in each of the individual soil samples (SOC/TN and SOC/TP, all in $\mathrm{g} / \mathrm{kg}$ ). Alpha diversity measures (Chao 1, Simpson, Shannon, observed OTUs, Goods coverage and Fisher index) and soil properties were used for significance analysis followed by one-way-analysis of variance with least-significant difference (LSD) at 0.05 level using SPSS version 19.0 software (IBM Corp., Armonk, NY, United States) to explore their distribution patterns in different ecological types. To detect the strength of edaphic drivers upon bacterial communities' structure and OTU associations with ecological types, a redundancy analysis (RDA) was made by CANOCO for Windows 4.5 (Ithaca, NY, United States). The R environment ${ }^{1}$ with version 3.6.3 was also performed for statistical computing. Principal coordinate analysis (PCoA) plots were drawn to assess the similarity of soil bacterial community structures based on weighted Unifrac and Bray-Curtis distances by applying the vegan package in $\mathrm{R}$. Interactions with $P$-values $<0.01$ and a false discovery rate $<0.05$ among the most abundant OTUs and between these OTUs and edaphic variables were kept to generate correlation networks by using Gephi version 0.9.2 (Barberán et al., 2012). Heat map illustrating the correlations between edaphic variables and OTUs with $P$-values $<0.05$, and the relative frequencies of the most abundant OTUs $(>0.5 \%)$ was created by the pheatmap $\mathrm{R}$ package. The co-occurrence of OTUs in soil bacterial communities across five ecological types was also analyzed. To reduce network complexity and facilitate the identification of the core soil bacterial communities, OTUs with more than five sequences were selected for further analysis (Barberán et al., 2012). A valid co-occurrence event to be a robust correlation was considered by using Gephi, when the Spearman's correlation coefficient $(r)$ was $>0.6$ and statistically significant $(P)$ was $<0.01$ (Junker and Schreiber,

${ }^{1}$ http://www.r-project.org
2011; Barberán et al., 2012; Ma et al., 2016). Partial Least Squares Path Modeling (PLS-PM; Tenenhaus et al., 2005; Zhong et al., 2020) was used to explore the relationships among soil bacterial community compositions (including main phyla with the relative abundance higher than $0.1 \%$ ) and alpha diversities, soil properties ( $\mathrm{pH}, \mathrm{SOC}, \mathrm{TN}, \mathrm{TP}, \mathrm{E}-\mathrm{Ca}$ and $\mathrm{E}-\mathrm{Mg}$ ), and plant richness factors (plant Gleason index) by using the plspm package, boot package and vegan package in $\mathrm{R}$. Their correlations were evaluated by using PASSaGE 2 based on Partial Mantel (PM) test, which could eliminate the collinearity of variables. Variation partitioning analysis (VPA) was performed using the Vegan package in $\mathrm{R}$ to quantitatively evaluate the contribution of soil properties and plant richness factors to the variation of soil bacterial community compositions and alpha diversities. Analysis of similarity (ANOSIM) tests was conducted with the vegan $R$ package to determine the statistical differences in five ecological types by permutation of group membership with 999 replicates, where the test statistic $R$, which measures the strength of the results, ranges from -1 to $1(R=1$ signifies differences between groups, while $R=0$ signifies that the groups are identical; Anderson and Walsh, 2013).

\section{RESULTS}

\section{Bulk Soil Physicochemical Characteristics}

Soil SOC, TN, and E-Mg contents increased from GL to PF, $\mathrm{AF}$, and $\mathrm{RD}$ after returning farmland to forests, which exhibited significant differences between $\mathrm{RD}$ and other ecological types. Soil $\mathrm{pH}$ values showed a high spatial heterogeneity, though the significant difference in soil $\mathrm{pH}$ values was observed between $\mathrm{RD}$ and other ecological types. High spatial heterogeneity in soil TP and E-Ca contents, and soil C:P ratios were also observed among five ecological types. In contrast, soil $\mathrm{C}: \mathrm{N}$ ratios were clearly decreasing along the successional gradients from CL to $\mathrm{RD}$. Interestingly, soil $\mathrm{pH}$ values, soil SOC, TN, E-Ca, and $\mathrm{E}-\mathrm{Mg}$ contents, and soil C:P ratios in $\mathrm{CL}$ were lower than those in $\mathrm{RD}$, though soil TP contents and C:N ratios in CL were higher than those in RD.

\section{Soil Bacterial Community Structure and Diversity Under the Influence of Ecological Types}

Of all the reads, we found that $>77.92 \%$ of the $16 \mathrm{~S}$ sequences were assigned to bacteria, where $>69.79 \%$ of the $16 \mathrm{~S}$ sequences were assigned to 12 bacterial phyla (every sample's relative frequency $>0.1 \%$ ), with the remainder being unassigned to a known bacterial phylum. The dominate phyla Acidobacteria, Bacteroidetes, Proteobacteria, Chloroflexi, Verrucomicrobia, Actinobacteria, Firmicutes, Planctomycetes, Gemmatimonadetes, Rokubacteria, Armatimonadetes, and Latescibacteria had the different mean relative frequency across five ecological types (Figure 2).

In general, soil bacterial alpha diversity indices increased from $\mathrm{CL}$ to GL, $\mathrm{AF} / \mathrm{PF}$ and $\mathrm{RD}$ (Table 2). The difference of 


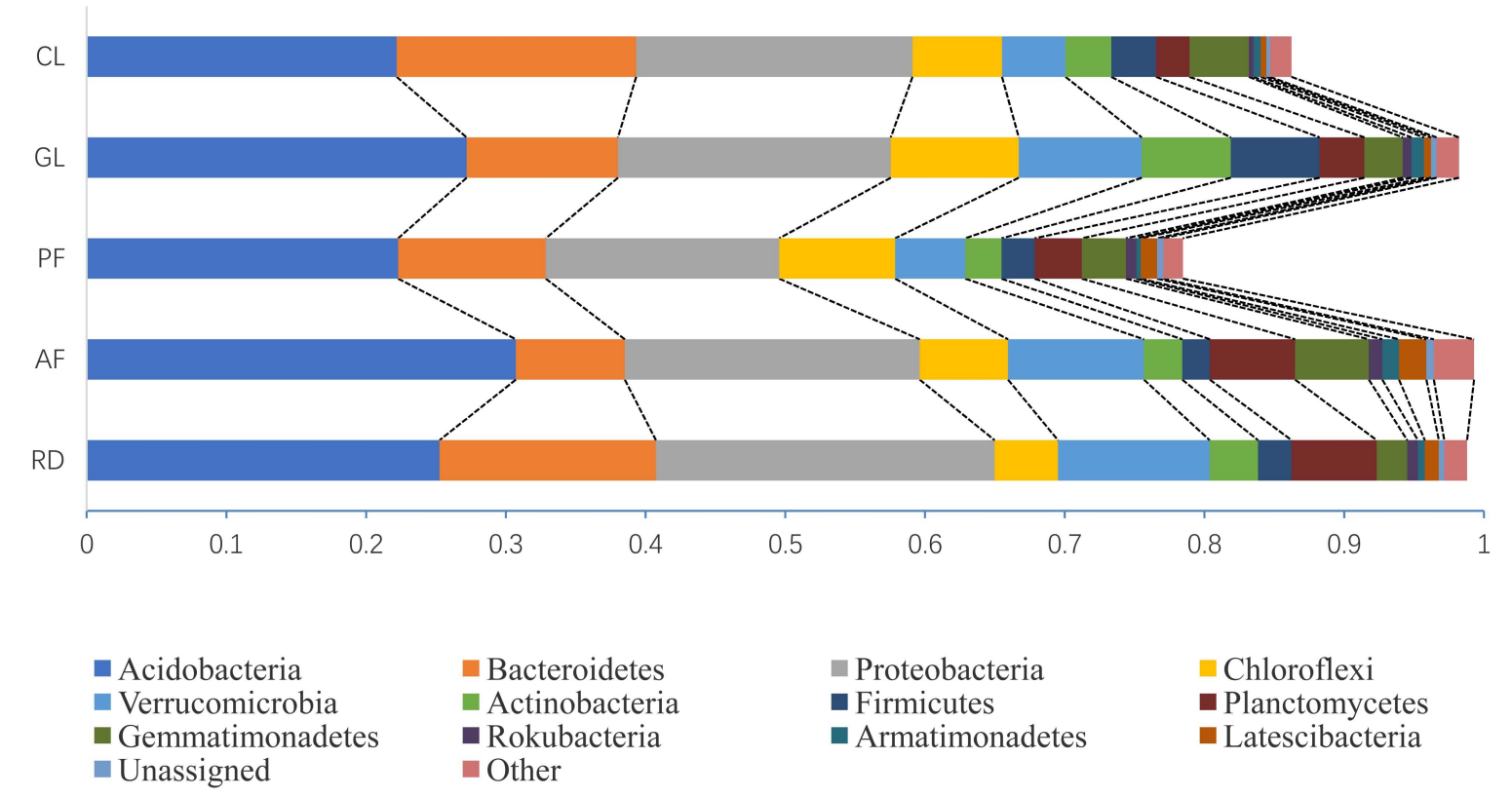

FIGURE 2 | Comparison of the quantitative contribution of the sequences affiliated with different bacterial phyla to the total number of sequences from five ecological types. Sequences not classified to any known phylum are included as unassigned bacteria. In each ecological type, bacterial phyla with a largest relative frequency of less than $0.1 \%$ are included as others.

TABLE 2 | Mean alpha diversity in five ecological types.

\begin{tabular}{llllclc}
\hline Type & Chao 1 & Shannon & Simpson & Observed OTUs & Goods coverage (\%) & Fisher index \\
\hline CL & $1987 \pm 55 b$ & $7.06 \pm 0.17 b$ & $0.96 \pm 0.01 b$ & $1390 \pm 33 b$ & $97.23 \pm 0.09 a b$ & $344.75 \pm 0.83 b$ \\
GL & $1906 \pm 121 b$ & $7.28 \pm 0.23 b$ & $0.97 \pm 0.01 a b$ & $1403 \pm 79 b$ & $97.36 \pm 0.17 a$ & $349.56 \pm 26.37 b$ \\
PF & $2165 \pm 42 a b$ & $7.15 \pm 0.29 b$ & $0.94 \pm 0.02 b$ & $1503 \pm 29 a b$ & $96.99 \pm 0.04 b$ & $382.08 \pm 9.61 a b$ \\
AF & $2252 \pm 71 a$ & $8.43 \pm 0.05 a$ & $0.99 \pm 0.00 a$ & $1683 \pm 55 a$ & $96.98 \pm 0.10 b$ & $444.93 \pm 19.72 a$ \\
RD & $2231 \pm 79 a$ & $8.32 \pm 0.19 a$ & $0.99 \pm 0.00 a$ & $1664 \pm 69 a$ & $97.04 \pm 0.09 a b$ & $438.34 \pm 24.48 a$
\end{tabular}

Values are the mean of analytical replicates for each sample \pm standard deviations. Statistical pairwise multiple comparisons of data homogeneity were carried out by the LSD test: means with the same letter in the same column are not significantly different at $P<0.05$.

soil bacterial beta diversity was visualized by the PCoA tool with an unweighted UniFrac and Bray-Curtis distance matrix, though PF and CL had some overlaps. Moreover, ANOSIM revealed that KRD control exerted a strong influence on the soil bacteria communities with significant statistical differences (Bray-Curtis $-R=0.413, P=0.003$, and unweighted UniFrac$R=0.477, P=0.001$ ), as seen in Figure 3. The two relations in five ecological types based on ANOSIM have shown that AF/CL, $\mathrm{AF} / \mathrm{GL}$ and $\mathrm{CL} / \mathrm{RD}$ had the significant statistical differences $(P<0.001)$ (Supplementary Figure 1).

\section{Distribution of Soil Bacterial Community Compositions in Five Ecological Types}

The relative abundances of Verrucomicrobia, Planctomycetes, Patescibacteria, Rokubacteria, FCPU426, and Dependentiae increased significantly with plant Gleason index, while the relative abundances of Nitrospirae decreased significantly with plant Gleason index (Figure 4). Moreover, the heat map clearly suggested that ecological types had a greater effect on most frequent OTU occurrences (Figure 5B). However, only Candidatus Udaeobacter (OTU11), Chthoniobacterales (OTU8) and Pedosphaeraceae (OTU40) were detected as the most frequent bacteria taxa in the dominate phylum Verrucomicrobia (Figure 5B) and increased significantly with plant Gleason index (Supplementary Figure 2).

\section{Relationships of Soil Bacterial Communities With Edaphic Properties in Five Ecological Types}

Redundancy analysis revealed that the distribution of 27 top OTUs was strongly affected by ecological types (Figure 5A). Permutation test analysis revealed that the 27 top OTUs distribution across all samples could be mainly explained by the RDA1 axis $(F=4.4, P=0.002)$, significantly correlating with E-Ca $(F=5.5, P=0.002)$, TP $(F=4.3, P=0.006)$, $\mathrm{pH}$ $(F=3.9, P=0.004)$ and plant Gleason index $(F=2.4, P=0.048)$. Moreover, the edaphic variables explained $73.5 \%$ of the soil bacterial variance, with axis 1 explaining $33.81 \%$ of the variance 


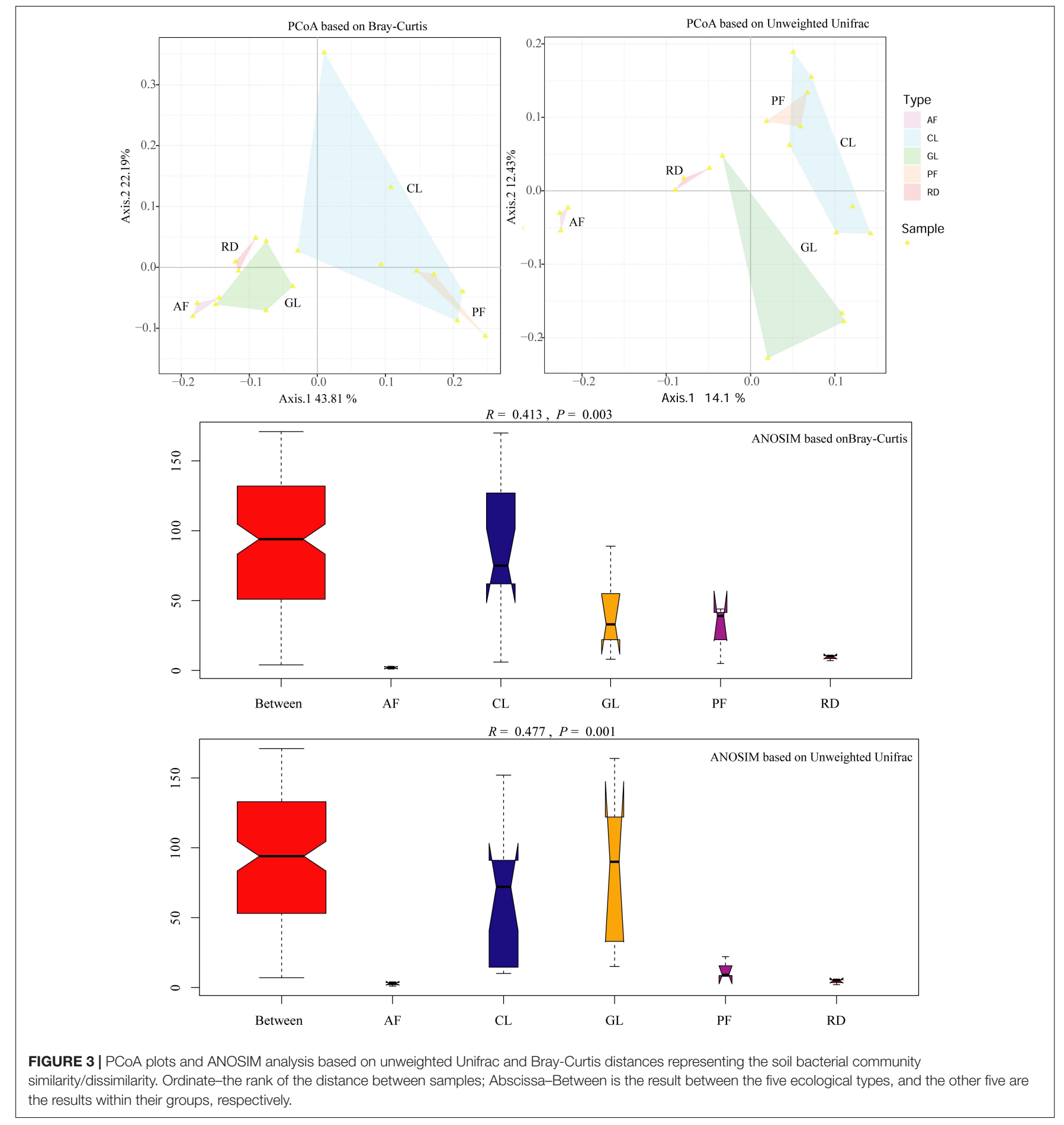

and axis 2 explaining another 21.09\%. A Pearson correlationbased heat map was drawn to illustrate associations between the most abundant OTUs and edaphic variables (Figure 5C). Network analysis showed associations between co-occurring OTUs with edaphic variables (Figure 5D), e.g., the most frequent Verrucomicrobia OTUs (8 and 11) negatively related to TP and E-Mg, and OTU 40 positively related with TN and SOC, as also seen in Figures 5A,C.
To better explore the key drivers shaping soil bacterial communities in five ecological types, a variety of statistical methods was used in our study. The PM test showed that plant richness (that is, Gleason index) had the significant $(r=0.314$, $P=0.002$ ) effects on soil properties ( $\mathrm{pH}, \mathrm{SOC}, \mathrm{TN}, \mathrm{E}-\mathrm{Ca}, \mathrm{E}-\mathrm{Mg}$, and TP). Plant richness or soil properties had no significant $(P>0.05)$ effects on soil bacterial community composition (Table 3). Though plant richness had no significant $(P>0.05)$ 


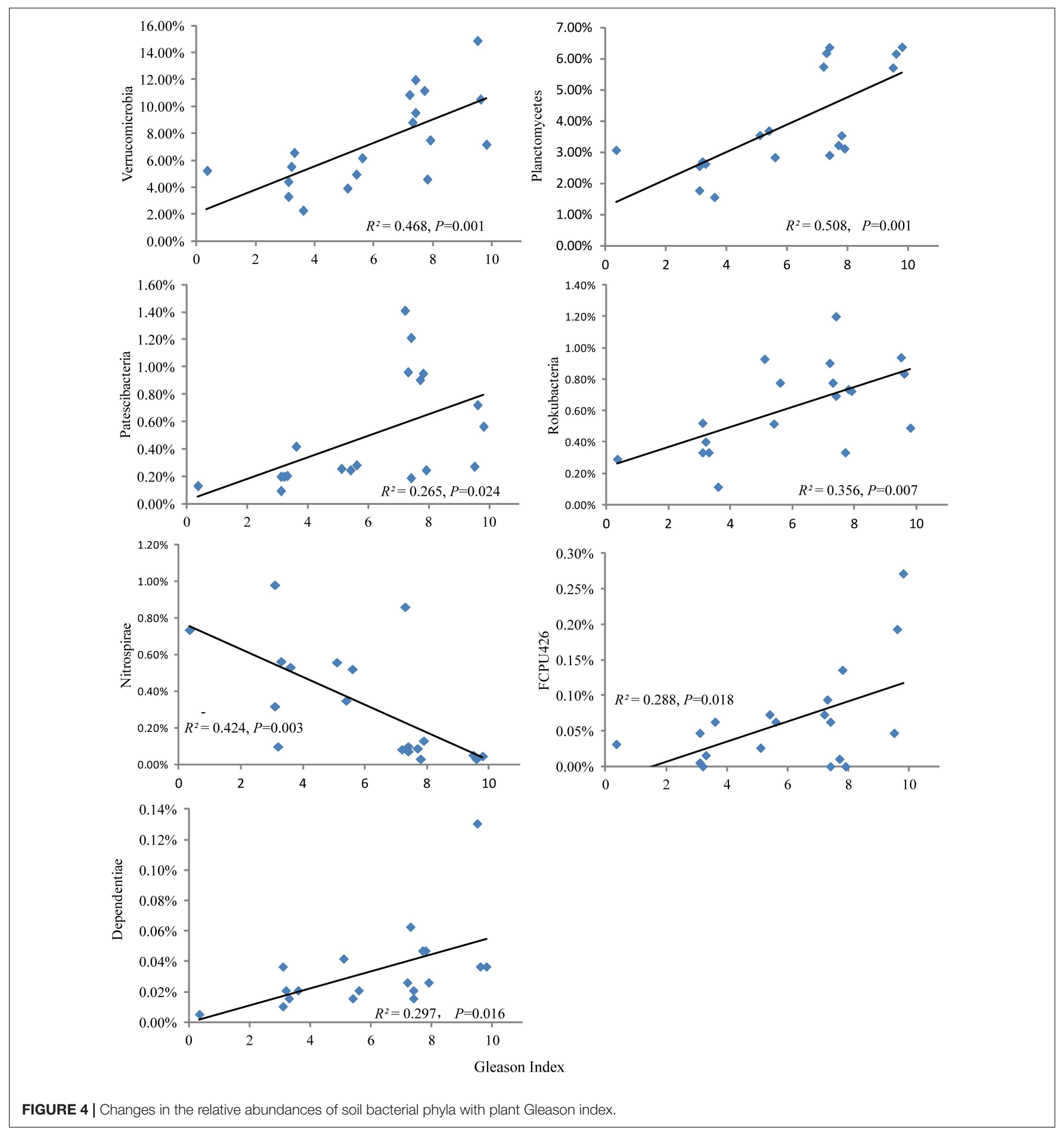

effects on soil bacterial alpha diversity, soil properties had the significant $(P<0.01)$ effects on soil bacterial alpha diversity (Table 3). C: $\mathrm{P}$ ratios also have the significant influence on soil bacterial community composition $(r=0.29, P=0.010)$. Besides, the Partial Least Squares (PLS) path model was applied in our study to integrate the complex interrelationships among edaphic factors and soil bacterial communities (Figure 6). The PLS model was represented here with the GoF 0.50. According to the PLS-PM, plant richness exerted significant direct effects on soil properties $(r=0.55, P=0.017)$, which exerted significant direct effects on soil bacterial community composition $(r=0.77$, $P=0.005)$ and exerted significant effects on soil bacterial alpha diversity $(r=0.78, P=0.023)$. Interestingly, the changes of bacterial community composition had the significant direct effect on soil bacterial alpha diversity $(r=0.83, P=0.034)$. Moreover, the variance partitioning showed that plant richness 
A

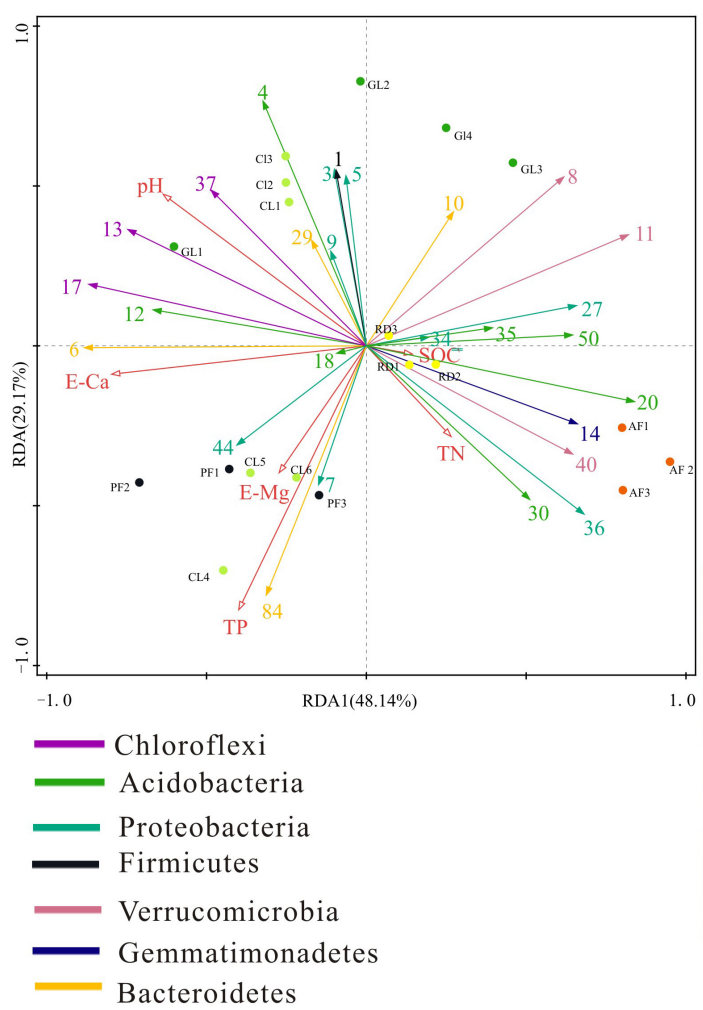

B

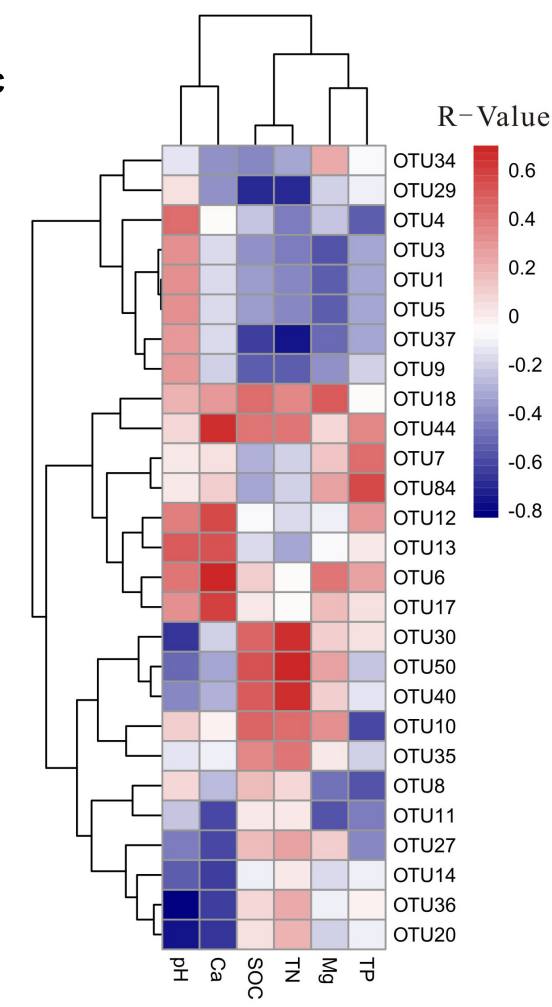

D

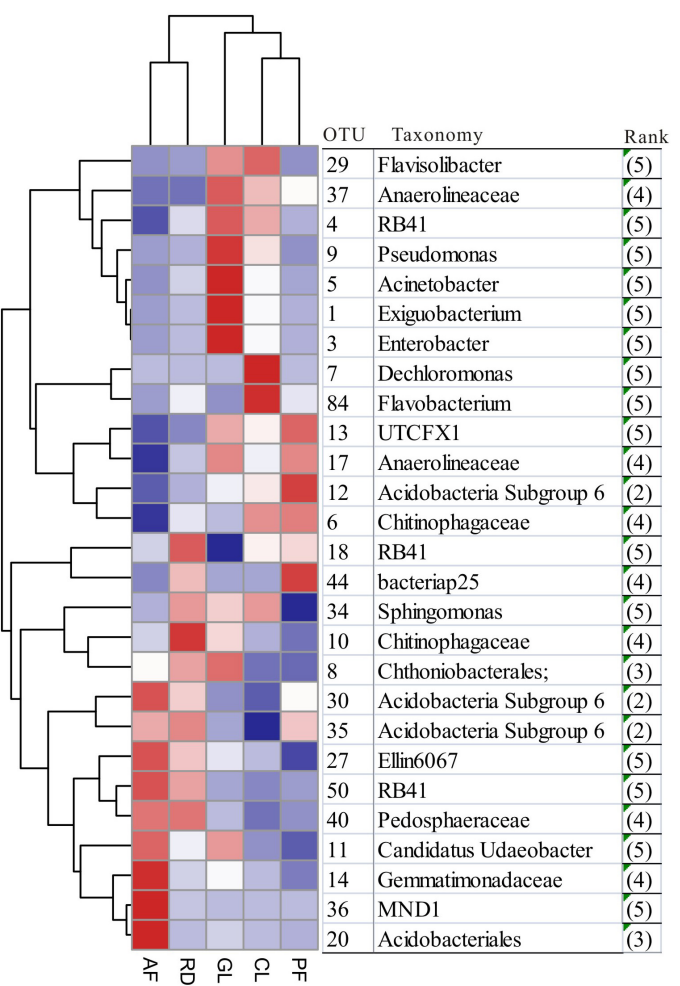

Taxonomy Ranks (): 1-Phylum; 2-Class;

3-Order; 4-Family; 5-Genus

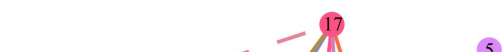


TABLE 3 | Influence of plant richness and soil properties on bacterial community composition and alpha diversity by partial Mantel test.

\begin{tabular}{|c|c|c|c|c|c|c|c|}
\hline \multirow{2}{*}{$\begin{array}{l}\text { Effect of } \\
\text { Controlling for }\end{array}$} & & \multicolumn{2}{|c|}{ Plant richness ${ }^{a}$} & \multicolumn{2}{|c|}{ Soil } & \multirow[t]{2}{*}{$\mathrm{C}: \mathrm{N}$ ratios } & \multirow[t]{2}{*}{ C:P ratios } \\
\hline & & & Soil $^{b}$ & & Plant richness & & \\
\hline \multirow[t]{2}{*}{ Bacterial community composition ${ }^{c}$} & Correlation & 0.156 & 0.116 & 0.148 & 0.105 & 0.033 & 0.291 \\
\hline & $P$-value & 0.217 & 0.301 & 0.328 & 0.453 & 0.823 & 0.010 \\
\hline \multirow[t]{2}{*}{ Alpha diversity ${ }^{d}$} & Correlation & 0.053 & -0.052 & 0.319 & 0.319 & 0.026 & 0.015 \\
\hline & $P$-value & 0.617 & 0.607 & 0.009 & 0.006 & 0.829 & 0.975 \\
\hline
\end{tabular}

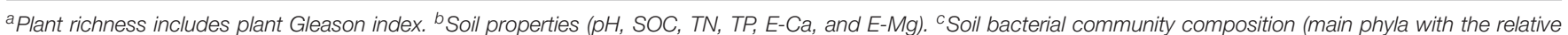
abundance higher than 0.1\%). 'Alpha diversity (Chao 1, Simpson and Shannon, observed OTUs, Goods coverage, and Fisher index).

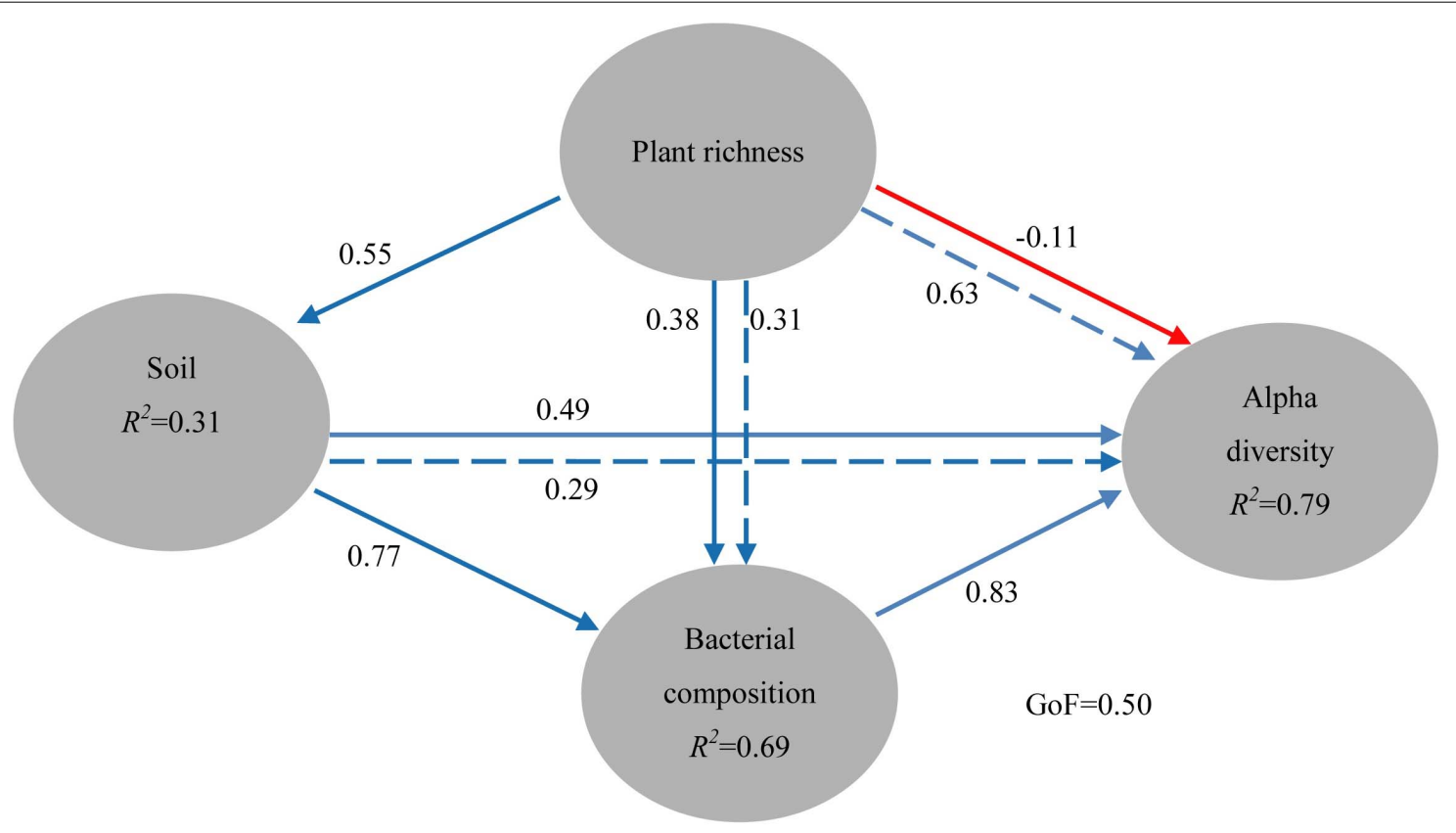

FIGURE 6 | Directed graph of the PLS-PM of plant richness effects on soil properties (pH, SOC, TN, TP, E-Ca, and E-Mg), and soil bacterial community composition (main phyla with the relative abundance higher than 0.1\%) and alpha diversity (Chao 1, Simpson and Shannon, observed OTUs, Goods coverage, Fisher index). The path coefficients and the explained variability $\left(R^{2}\right)$ in our study were calculated after 999 bootstraps. Blue solid arrows indicate positive direct effects, red solid arrows indicate negative direct effects, blue dashed arrows indicate positive indirect effects. Models with different structures were assessed using the Goodness of Fit (GoF) statistic, a measure of the overall prediction performance. For the PLS-PM represented here, the GoF was 0.50.

can explain $5.6 \%$ and $34.0 \%$ of the variation about bacterial community composition and alpha diversity, soil properties can explain $34.0 \%$ and $35.6 \%$ of the variation about bacterial community composition and alpha diversity, and the variations of bacterial community composition and alpha diversity are mainly explained by soil properties (34.1\%) and plant richness (34.0\%) (Supplementary Figure 3).

\section{Co-occurrence Patterns of Soil Bacteria in Five Ecological Types}

Co-occurrence network analysis revealed remarkable differences in five ecological types (Figure 7). The clustering coefficient in CL, GL, PF, AF, and RD was 0.783, 0.986, 0.996, 0.997, and 0.997, respectively, and the modularity index in $\mathrm{CL}, \mathrm{GL}, \mathrm{PF}, \mathrm{AF}$, and $\mathrm{RD}$ was $0.837,0.908,0.812,0.826$, and 0.817 , respectively. The resulting soil microbial networks in CL, GL, PF, AF, and RD were consisted of 113, 153, 249, 344 and 318 nodes (OTUs) as well as $233,581,4314,7405$, and 6768 edges, respectively. The average degree or node connectivity in CL, GL, PF, AF, and RD was $4.12,7.60,34.65,43.05$, and 42.57 , respectively. In addition, the soil microbial network in GL, PF, AF, and RD was comprised of highly connected OTUs $(37.97,17.73,21.53$, and 21.28 edges per node, respectively) structured among densely connected groups of modules (nodes), where a clustered topology was formed. In contrast, the soil microbial network in CL was comprised of lowly connected OTUs (2.06 edges per node).

All the top six bacteria in five co-occurrence networks were classified into Proteobacteria, Acidobacteria, Bacteroidetes, Verrucomicrobia, Gemmatimonadetes, Actinobacteria, Chloroflexi and Planctomycetes. Interestingly, Firmicutes dominated in the co-occurrence network of $\mathrm{CL}$ and Actinobacteria dominated in the co-occurrence network of GL, PF, AF and RD. Besides, Candidatus Udaeobacter, 


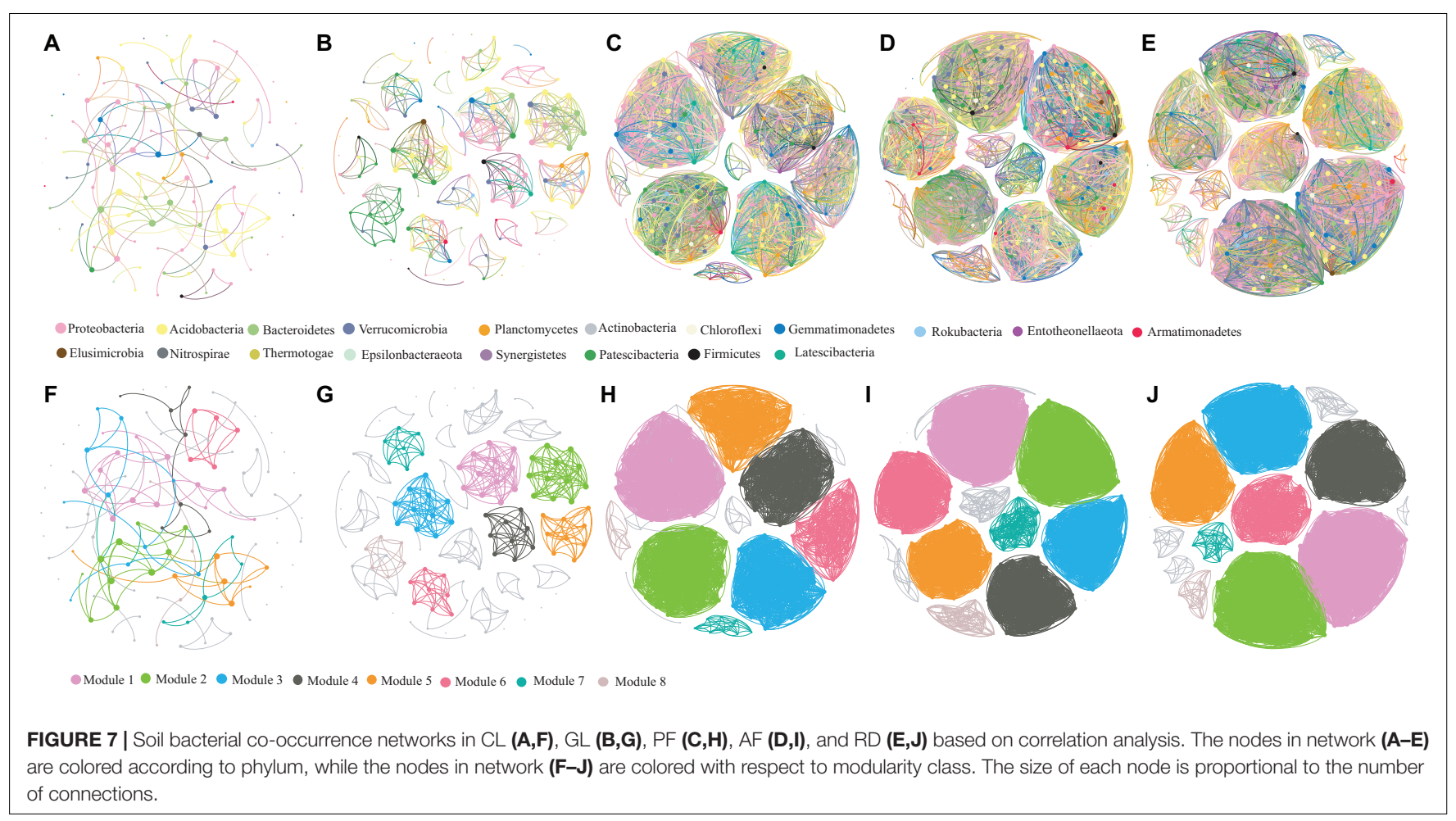

Chthoniobacterales, and Pedosphaeraceae were identified as the top three genera in five co-occurrence networks.

\section{DISCUSSION}

\section{Responses of Bulk Soil Physicochemical Characteristics to Ecological Types in KRD Control Area}

Reforestation can increase SOC accumulation and N stock across the chronosequence ( $\mathrm{Li}$ et al., 2012, 2021; Tong et al., 2018). In the present study, the generally increased soil TN and SOC from grass land to secondary forest land (that is, AF or PF) and natural land (that is, RD) infers that returning farmland to forests promotes the accumulation of organic materials in KRD control areas, in accordance with previous studies (Xue et al., 2017; Tong et al., 2018). The link between ecosystem restoration and SOC as well as $\mathrm{N}$ accumulation is driven by the translation of plant residues and root exudation to belowground $\mathrm{C}$ and $\mathrm{N}$ storage (Shao et al., 2019). Moreover, rich calcium in karst soil plays another active role in SOC stabilization (Rowley et al., 2018). In contrast, low mean SOC content with $27.13 \mathrm{~g} / \mathrm{kg}$ in corn land (the mean SOC content in croplands of southwest China is $24.5 \mathrm{~g} / \mathrm{kg}$ ) may have been due to the combined application of farm manure and chemical fertilizer. Though the mean soil C:N ratios in China was 11.9 (Tian et al., 2010), the soil samples in our study had the mean soil C:N ratios $>25.44$, which generally decreased from grass land to secondary forest land and natural land. The high $\mathrm{C}: \mathrm{N}$ ratios in our study are driven by additional biotic factors (Shao et al., 2019) and tightly linked to soil, water and nutrient loss/leakage in karst regions with the karst fissures or karren characters, which have been observed by the continuing drain of $\mathrm{NO}_{3}{ }^{-}$from soil into epikarst spring (Li et al., 2010; Peng et al., 2019). In addition to ecosystem restoration effects on decreased $\mathrm{C}: \mathrm{N}$ ratios during reforestation chronosequence, we speculate that ectomycorrhizal fungi that can selective decompose and uptake organic $\mathrm{N}$ will drive $\mathrm{N}$ limitation of plant roots and free-living decomposers, which is consistent with slowing soil $\mathrm{C}$ respiration and increased soil C storage, as previous observed (Averill and Hawkes, 2016). Unlike the soil $\mathrm{C}$ and $\mathrm{N}$, soil $\mathrm{P}$ is majorly provided by the weathering of the parent material (Walker and Adams, 1958). In this study, soil TP exhibited a high spatial heterogeneity and all soil samples had mean C:P ratios $<38$ (the mean soil C:P ratios in China was 61) (Tian et al., 2010), indicating that C:P ratios might change with environmental factors although "Redfieldlike" interactions among $\mathrm{C}$ and $\mathrm{P}$ may exist in soil (Cleveland and Liptzin, 2007). Moreover, the changed C:P ratios and TP content may be due to soil $\mathrm{P}$ leaking dominated by the interactive effects of runoff losses, and temperature or microorganism influence on weathered soils in tropical-subtropical regions (Richardson and Simpson, 2011; Peng et al., 2019). Thus, we found that TP content almost decreased and C:P ratios almost increased across the chronosequence, suggesting high $\mathrm{P}$ input in cropland and low P supply leading to high C:P (Tian et al., 2010). In contrast, the land covered by Pinus yunnanensis forest exhibited low C:P ratios, which may be relating to high soil weathering rate caused by coniferous afforestation with soil acidification activity (Brand et al., 1986). Considering that soil C:P ratios $<200$ implies net 
mineralization (Paul, 2007) and soil C:N ratios $>25$ indicates organic matter accumulation faster than decomposition (Bui and Henderson, 2013), our results inferred $\mathrm{N}$ and $\mathrm{P}$ co-limitation in the karst ecosystem.

In carbonate area, calcareous soil can reduce acidification activity caused by plants and soil disturbances, consequently the soil exhibited $\mathrm{pH}$ values $>6.24$. While the role of plants in reusing soil magnesium and in uptaking calcium accumulated in plant leaves has been well established (Marschner, 2011), soil calcium and magnesium as the essential mineral elements for plants and microbes exhibited high spatial heterogeneity. However, the changed edaphic properties during ecosystem restoration cannot be adequately explained without soil microorganism which is not only the main engines and biomass of biogeochemical cycle in terrestrial ecosystem (Delgado-Baquerizo et al., 2018, 2019; Wagg et al., 2019). In this respect, we speculate the changed edaphic properties are driven by biotic factors, specifically bacteria, the quantitatively dominant microorganisms in soil ecosystems, that link ecosystem restoration and soil physicochemical variation (Delgado-Baquerizo et al., 2018, 2019; Shao et al., 2019; Wagg et al., 2019).

\section{The Impacts of Ecological Types on the Differentiation of Soil Bacterial Communities in KRD Control Area}

This study and many previous studies showed that vegetation restoration influenced soil properties (Jiang et al., 2014; Li et al., 2014; Chang et al., 2018; Bai et al., 2019). Considering that microbial processes relating to element cycling in soil, the changed soil properties in turn can affect soil bacterial communities (Delgado-Baquerizo et al., 2018, 2019; Wagg et al., 2019). In the present study, the differentiation of soil bacterial communities in five ecological types indicated that returning farmland to forests might play important roles in shaping soil bacterial community diversity, as shown by ANOSIM analysis and PCoA plots. However, the similarity between corn land and Pinus yunnanensis forest was observed based on both ANOSIM analysis and PCoA plots, indicating that managed ecosystems have the similar beta diversity, which is a key concept about what controls diversity in ecological communities (Condit et al., 2002). That is, artificial selection illustrates an important role in shaping the whole ecosystems composed by thousands of species and millions of individuals (Swenson et al., 2000). In contrast, an enhanced dissimilarity between the natural ecosystems and the sustainable management ecosystems was observed in our study. Previous studies have shown that soil bacterial community structures can be shaped by environmental factors, such as $\mathrm{pH}$ (Fierer and Jackson, 2006) and calcium (Xue et al., 2017). In the present study, soil $\mathrm{pH}$ and E-Ca were closely correlated with soil bacterial distribution in five ecological types. The strong correlation between soil $\mathrm{pH}$ and bacterial distribution may have been due to each type of microorganism having an optimal $\mathrm{pH}$ value, and a slight change in $\mathrm{pH}$ favoring distinct bacterial taxa (Fierer and Jackson, 2006; Xue et al., 2017). Calcium is the important nutrient required by bacteria for growth and cell maintenance, signaling pathways regulating, gene regulation, cellular communications and responsiveness to both the intracellular and extracellular environments, biomacromolecular structural modification, and bacterial biofilm formation (Xue et al., 2017; Wang et al., 2019). On the contrary, bacteria can induce calcium carbonate precipitation as part of their basic metabolic activities in karst soil providing sufficient calcium and carbonate ions (Dhami et al., 2013), which has been linked to sequestration of atmospheric $\mathrm{CO}_{2}$ ( $\mathrm{Li}$ et al., 2015b). Therefore, the significant positive correlations between soil bacterial distribution and $\mathrm{pH}$ as well as calcium imply that they are the important factors for shaping soil bacterial communities. Microorganisms are integral to soil $\mathrm{P}$ cycle and a small component of total soil $\mathrm{P}$ is directly available for microbial uptake (Richardson and Simpson, 2011). In this study, soil bacterial distribution demonstrated significant positive correlations with phosphorus, which implies that the available $\mathrm{P}$ content acts as a determining factor in shaping soil bacterial populations. The $\mathrm{P}$ limitation can increase the concentrations of microbial residues and might be favorable for the stability of SOC by through affecting the soil bacterial communities (Yuan et al., 2020). This findings are supported by significant relationship between $\mathrm{C}: \mathrm{P}$ ratios and soil bacterial community composition. In contrast, $\mathrm{C}: \mathrm{N}$ ratios have no significant relationships with soil bacterial diversity and community composition, though the significant relationships of C:N ratio with bacterial diversity and community composition have been reported by Xue et al. (2017). This is unsurprising, however, considering that soil, the continuous spatio-temporal heterogeneity with high spatial variability, harbors vast soil microorganisms (Yuan, 1997; Harris, 2009; Jiang et al., 2014; Delgado-Baquerizo et al., 2018, 2019), where bacteria play an important role in the metabolism of one$\mathrm{C}$ compounds and fungi are the key drivers of decomposition processes (Delgado-Baquerizo et al., 2018, 2019; Shao et al., 2019; Wagg et al., 2019). Though fungal dynamics in response to environmental gradients is much scarcer than for bacterial communities (Bastida et al., 2016), different bacteria to fungi ratios altered by the habitat changes induced the different contributions from microbial catabolism and/or anabolism driving soil C and $\mathrm{N}$ dynamics (Wagg et al., 2019; Zhong et al., 2020). Therefore, we speculate the changed allocation between plant and soil microorganisms may lead to the out-sync with carbon and nitrogen, though the contribution of fungi was not directly evaluate in our study. In addition, plant Gleason index is another important factor driving karst soil bacterial distribution. That is, plant diversity can enhance the range of food resources available for soil microbes (Van der Heijden et al., 2008; Lamb et al., 2011; Lange et al., 2014; Zuo et al., 2016). But despite all that, we could not identify $\mathrm{pH}$, calcium, phosphorus, plant richness, or all four, which is the key factor(s) determining microbial community structure.

Instead of focusing on the relationship between individual edaphic factors and soil bacterial communities, latent variables of plant richness, soil properties, soil bacterial communities, and soil bacterial diversity as combinations of related factors were used in our PLS-PM, which could well interpret the inter-relationships among variables (Tenenhaus et al., 2005; Zhong et al., 2020). In the present study, it was found that 
plant richness had important indirect effects on soil bacterial community diversity and composition mainly through the effects on soil properties, as exhibited by Supplementary Figure 3. Recently, several studies have shown that community assembly of soil bacteria was connected to ecosystems (DelgadoBaquerizo et al., 2018, 2019; Wagg et al., 2019) and concluded that greater diversity would promote the metabolism of plant inputs in soil and hence alter the compositions and functionalities of the soil microbial community (Wagg et al., 2019). Here, our result provided evidence that soil bacterial community was mediated by ecological types through the changed soil properties.

\section{The Contributions of KRD Control to Soil Bacterial Communities}

The interactions among the vast diversity of microbes in soil are direct or indirect, such as competition, facilitation, and inhibition (Wagg et al., 2019), which can be reveled by microbial co-occurrence analyses (Barberán et al., 2012; Ma et al., 2016; Xue et al., 2017). The modularity index $>0.4$ indicates that the network has a modular structure (Xue et al., 2017). The most abundant phyla in the soil bacterial co-occurrence network showed that Firmicutes were dominating in CL and Actinobacteria were dominating in GL, PF, AF, and RD. That is, all these members of the phylum Firmicutes are well known for their facultative to strict anaerobic metabolism (Johnson et al., 2008). Extreme environmental conditions such as karst farmlands can favor Endospore-forming Firmicutes deploying a myriad of survival strategies to resist adverse conditions (Filippidou et al., 2016; Gupta et al., 2018). In contrast, Actinobacteria are known as degraders of highly recalcitrant organic materials, including substances recycling, polymer degradation, and bioactive molecule production (Barka et al., 2016). The link between ecosystem restoration and dominant Actinobacteria suggests that the decomposition, transformation and stabilization of the accumulated organic materials via input of plant residues and root exudation, and the contribution of microbial necromass are driven by this dominant bacterial functional group (Barka et al., 2016; Delgado-Baquerizo et al., 2018). Thus, it is critical that future research describes the contribution of actinobacterial species in biogeochemical cycles of organic materials. Though Acidobacteria, Bacteroidetes, Proteobacteria, Chloroflexi, Verrucomicrobia, Planctomycetes, Gemmatimonadetes were the top 7 phyla in the co-occurrence network, only Verrucomicrobia demonstrated stronger correlations with ecological types, indicating that these dominant bacteria will be critical drivers, or indicators, of key soil processes worldwide (Delgado-Baquerizo et al., 2018). Verrucomicrobia usually increase consistently with ecological succession (Bergmann et al., 2011; Jangid et al., 2011; Shen et al., 2017) and have the oligotrophic and slow growth rate life history strategy (Bergmann et al., 2011), which allows them exploit sparse resources (such as $\mathrm{N}$ and $\mathrm{P}$ co-limitation) in karst soils. The fact that three top OTUs (Candidatus Udaeobacter, Chthoniobacterales, and Pedosphaeraceae) demonstrating stronger correlations with ecological types were also recognized in the co-occurrence networks, indicating their important ecosystem multifunctionality involved in SOC accumulation and $\mathrm{N}$ stock across the chronosequence. Candidatus Udaeobacter, an aerobic heterotroph encoding many amino acid and vitamin transporters, which can minimize cellular architecture and sacrifice metabolic versatility for efficiency to become dominant in the soil environment, have the capacity to store surplus carbon as glycogen or starch (Brewer et al., 2016). Chthoniobacterales are very common in soils (Sangwan et al., 2004) and can make rapid responses to changes in the availability of substrates and oxygen in soil (Hirsch et al., 2017). Pedosphaeraceae has been identified as an important species in soil biogeochemical cycle, yet a better understanding of their roles in soil bacterial co-occurrence networks is still needed in the future (Zhang et al., 2019). However, a recent study revealed that Bryobacter, GRWP33-30, and Rhizomicrobium were the keystone karst bacteria in Fuyuan County, Yunnan Province (Xue et al., 2017). This is unsurprising, however, considering that only a small fraction of soil bacteria is typically shared between any pair of unique soil samples (Delgado-Baquerizo et al., 2018). Therefore, the three top OTUs in our study will be critical drivers, or indicators, of key soil biogeochemical processes. Though rare soil bacteria are also the drivers of key functions in terrestrial ecosystems, which may be due to effects that are disproportionately large given their abundance or via the provision of insurance effects (Jousset et al., 2017), their roles in biogeochemical cycles is far less clear (Liang et al., 2020). Thus, it is critical that future research describes the contribution of rare soil bacteria driving ecosystem multifunctionality.

Soil microbial network complexity varies with their habitat conditions (Ma et al., 2016; Banerjee et al., 2019; Xue et al., 2020). For instance, soil microbial network complexity in late successional fields was higher than that in early successional fields (Morriën et al., 2017) and agricultural intensification can reduce soil microbial network complexity (Banerjee et al., 2019). Besides, soil microbial network complexity indicates the stage of ecosystem stability and multifunctionality (Wagg et al., 2019). In the present study, soil microbial network complexity increased from corn land to grass land, forest and natural land, indicating that the lower network complexity of soil bacteria in corn land need additional management where nutrient-use efficiency is low and degradation of soil quality is serious, which accords with a recent study on KRD process in southwest China (Jiang et al., 2014). That is, disturbances such as cultivation and fertilization might eliminate certain functional soil bacteria (Neher, 1999; Huang et al., 2019). In contrast, soil microbial network complexity is much higher in natural land, though attainment of steady state equilibrium in natural ecosystems is rare (Neher, 1999). Based on global meta-analyses with more than 200 reforestation samples, it was found that ecosystem restoration, rather than the geographical distribution, is the dominant factor influencing the complexities of the soil microbiome (Shao et al., 2019). Compared to natural secondary forests (Alnus ferdinandicoburgii Schneid), the artificial secondary Pinus yunnanensis 
forests had the lower soil bacteria network complexity, which might be relating to the outbreaks of pine moth in Yunnan province, China due to the loss of certain functional soil microbe which can produce secondary metabolites in suppressing pathogens and against harmful insert (Schmidt et al., 2019). Therefore, the rich soil microbiota tends to suppress the severity of the attack by many soilborne plant pathogens (Garbeva et al., 2004). Moreover, the clustering coefficient values of soil bacterial co-occurrence network in $\mathrm{AF}$ similar to $\mathrm{RD}$ was higher than that in $\mathrm{PF}$, which demonstrates the similar microbe network complexity in natural secondary forests and natural ecosystem (Xue et al., 2017). It is possible that artificial re-vegetation promotes the ecological restoration and environment improvement, however, changes in belowground ecosystem lag behind the corresponding changes in aboveground ecosystem (Delgado-Baquerizo et al., 2018). By referring to the cooccurrence patterns of belowground ecosystem in future studies at a broader spatial-temporal scale in karst area, our result paves the way for predictive understanding the belowground diversity during ecosystem restoration, which in turn can help us to amend the strategy and orientation of ecological restoration.

\section{CONCLUSION}

In the present study, we revealed the differentiation of soil bacterial communities in five ecological types in KRD control area. Our work suggested that plant richness was the key factor determining soil bacteria community, and soil microbial network complexity and stability. The key taxa, Candidatus Udaeobacter, Chthoniobacterales, and Pedosphaeraceae, which are classified into Verrucomicrobia, played the key roles in karst soil ecosystems. Finally, we demonstrated that natural secondary forests could promote the stability of soil ecosystems compared with the artificial secondary forests. That is, natural recovery is the suitable way for restoration and rehabilitation of degraded ecosystems. Thus, our study provide the methodology to appraise the interactions among soil-plant ecological network, though there is still a lot of work left to be done in the future.

\section{REFERENCES}

Anderson, M. J., and Walsh, D. C. (2013). PERMANOVA, ANOSIM, and the Mantel test in the face of heterogeneous dispersions: what null hypothesis are you testing? Ecol. Monogr. 83, 557-574.

Averill, C., and Hawkes, C. V. (2016). Ectomycorrhizal fungi slow soil carbon cycling. Ecol. Lett. 19, 937-947.

Bai, Y., Zha, X., and Chen, S. (2019). Effects of the vegetation restoration years on soil microbial community composition and biomass in degraded lands in Changting County. China. J. Forestry Res. 31, 1295-1308.

Banerjee, S., Walder, F., Büchi, L., Meyer, M., Held, A. Y., Gattinger, A., et al. (2019). Agricultural intensification reduces microbial network complexity and the abundance of keystone taxa in roots. ISME J. 13, 1722-1736.

Barberán, A., Bates, S., Casamayor, E. O., and Fierer, N. (2012). Using network analysis to explore co-occurrence patterns in soil microbial communities. ISME J. 6, 343-351.

\section{DATA AVAILABILITY STATEMENT}

The achieved raw sequence reads were submitted to the NCBI Sequence Read Archive under the accession numbers PRJNA471031 and PRJNA471162.

\section{AUTHOR CONTRIBUTIONS}

HY completed the soil sample collection. AS completed the data analysis and DNA extraction. QL and WM prepared the manuscript draft. QL designed the experiment, analyzed the data, and wrote the manuscript. WM helped with polishing the text and improving the structure and logic of the manuscript. All authors contributed to the article and approved the submitted version.

\section{FUNDING}

This work was supported by the National Key Research and Development Program of China (2016YFC0502501), Special Funds for Local Science and Technology Development Guided by the Central Government, China (GuikeZY20198009), and Fundamental Research Funds of CAGS (2020022).

\section{SUPPLEMENTARY MATERIAL}

The Supplementary Material for this article can be found online at: https://www.frontiersin.org/articles/10.3389/fmicb. 2021.636405/full\#supplementary-material

Supplementary Figure 1 | The two relations of ANOSIM analysis in five ecological types based on OTU abundance. Ordinate-the rank of the distance between samples; Abscissa-Between is the result between every two ecological types, and the other two are the results within their groups, respectively.

Supplementary Figure 2 | Changes of Candidatus Udaeobacter, Chthoniobacterales, and Pedosphaeraceae with plant Gleason index.

Supplementary Figure $\mathbf{3}$ | VPA shows the effects of plant richness and soil properties on soil bacterial community compositions (A) and alpha diversities (B).

Supplementary Table 1| The bacterial taxonomy of the soil samples.

Barka, E. A., Vatsa, P., Sanchez, L., Gaveau-Vaillant, N., Jacquard, C., Klenk, H. P., et al. (2016). Taxonomy, physiology, and natural products of Actinobacteria. Microbiol Mol. Biol. Rev. 80, 1-43.

Bastida, F., Torres, I. F., Moreno, J. L., Baldrian, P., Ondoño, S., Ruiz-Navarro, A., et al. (2016). The active microbial diversity drives ecosystem multifunctionality and is physiologically related to carbon availability in mediterranean semi-arid soils. Mol. Ecol. 25, 4660-4673.

Bergmann, G. T., Bates, S. T., Eilers, K. G., Lauber, C. L., Caporaso, J. G., Walters, W. A., et al. (2011). The under-recognized dominance of Verrucomicrobia in soil bacterial communities. Soil Biol. Biohem. 43, 1450-1455.

Beveridge, T. J. (1989). Role of cellular design in bacterial metal accumulation and mineralization. Anmu. Rev. Microbiol. 43, 147-171.

Brand, D. G., Kehoe, P., and Connors, M. (1986). Coniferous afforestation leads to soil acidification in central Ontario. Can. J. Forest Res. 16, 1389-1391.

Brewer, T. E., Handley, K. M., Carini, P., Gilbert, J. A., and Fierer, N. (2016). Genome reduction in an abundant and ubiquitous soil bacterium 'Candidatus Udaeobacter copiosus'. Nat. Microbiol. 2, 1-7. 
Bui, E. N., and Henderson, B. L. (2013). C: N: P stoichiometry in Australian soils with respect to vegetation and environmental factors. Plant Soil 373, 553-568.

Chang, J., Zhu, J., Xu, L., Su, H., Gao, Y., Cai, X., et al. (2018). Rational landuse types in the karst regions of China: insights from soil organic matter composition and stability. Catena 160, 345-353.

Cleveland, C. C., and Liptzin, D. (2007). C:N:P stoichiometry in soil: is there a "Redfield ratio" for the microbial biomass? Biogeochemistry 85, 235-252.

Condit, R., Pitman, N., Leigh, E. G., Chave, J., Terborgh, J., Foster, R. B., et al. (2002). Beta-diversity in tropical forest trees. Science 295, 666-669.

Dassen, S., Cortois, R., Martens, H., de Hollander, M., Kowalchuk, G. A., van der Putten, W. H., et al. (2017). Differential responses of soil bacteria, fungi, archaea and protists to plant species richness and plant functional group identity. Mol. Ecol. 26, 4085-4098.

Delgado-Baquerizo, M., Bardgett, R. D., Vitousek, P. M., Maestre, F. T., Williams, M. A., Eldridge, D. J., et al. (2019). Changes in belowground biodiversity during ecosystem development. P. Natl. Acad. Sci. 116, 6891-6896.

Delgado-Baquerizo, M., Oliverio, A. M., Brewer, T. E., Benavent-González, A., Eldridge, D. J., Bardgett, R. D., et al. (2018). A global atlas of the dominant bacteria found in soil. Science 359, 320-325.

Dhami, N. K., Reddy, M. S., and Mukherjee, A. (2013). Biomineralization of calcium carbonates and their engineered applications: a review. Front. Microbiol. 4:314. doi: 10.3389/fmicb.2013.00314

Duan, A., Liu, Y., and Wu, G. (2005). Heating status of the tibetan plateau from April to June and rainfall and atmospheric circulation anomaly over East Asia in midsummer. Sci. China Ser. D 48, 250-257.

Fierer, N., and Jackson, R. B. (2006). The diversity and biogeography of soil bacterial communities. P. Natl. Acad. Sci. U.S.A. 103, 626-631.

Filippidou, S., Wunderlin, T., Junier, T., Jeanneret, N., Dorador, C., Molina, V., et al. (2016). A combination of extreme environmental conditions favor the prevalence of endospore-forming firmicutes. Front. Microbiol. 7:1707. doi: 10. 3389/fmicb.2016.01707

Garbeva, P., van Veen, J. A., and van Elsas, J. D. (2004). Microbial diversity in soil: selection microbial populations by plant and soil type and implications for disease suppressiveness. Annu. Rev. Phytopathol. 42, 243-270.

Gupta, A., Dutta, A., Sarkary, J., Panigrahi, M. K., and Sar, P. (2018). Low-abundance members of the Firmicutes facilitate bioremediation of soil Impacted by highly acidic mine drainage from the Malanjkhand Copper Project. India. Front. Microbiol. 9:2882. doi: 10.3389/fmicb.2018. 02882

Harris, J. (2009). Soil microbial communities and restoration ecology: facilitators or followers? Science 325, 573-574.

Hirsch, P. R., Jhurreea, D., Williams, J. K., Murray, P. J., Scott, T., Misselbrook, T. H., et al. (2017). Soil resilience and recovery: rapid community responses to management changes. Plant Soil 412, 283-297.

Huang, F., Liu, Z., Mou, H., Zhang, P., and Jia, Z. (2019). Effects of different longterm farmland mulching practices on the loessial soil fungal community in a semiarid region of China. Appl. Soil. Ecol. 137, 111-119.

Jangid, K., Williams, M. A., Franzluebbers, A. J., Schmidt, T. M., Coleman, D. C., and Whitman, W. B. (2011). Land-use history has a stronger impact on soil microbial community composition than aboveground vegetation and soil properties. Soil Biol. Biohem. 43, 2184-2193.

Jiang, Z., Lian, Y., and Qin, X. (2014). Rocky desertification in Southwest China: impacts, causes, and restoration. Earth-Sci. Rev. 132, 1-12.

Johnson, D. B., Joulian, C., d'Hugues, P., and Hallberg, K. B. (2008). Sulfobacillus benefaciens sp. nov., an acidophilic facultative anaerobic Firmicute isolated from mineral bioleaching operations. Extremophiles 12:789.

Jousset, A., Bienhold, C., Chatzinotas, A., Gallien, L., Gobet, A., Kurm, V., et al. (2017). Where less may be more: how the rare biosphere pulls ecosystems strings. ISME J. 11, 853-862.

Junker, B. H., and Schreiber, F. (2011). Analysis of Biological Networks. Hoboken, NJ: John Wiley \& Sons.

Lamb, E. G., Kennedy, N., and Siciliano, S. D. (2011). Effects of plant species richness and evenness on soil microbial community diversity and function. Plant Soil 338, 483-495.

Lange, M., Habekost, M., Eisenhauer, N., Roscher, C., Bessler, H., Engels, C., et al. (2014). Biotic and abiotic properties mediating plant diversity effects on soil microbial communities in an experimental grassland. PLoS One 9:e96182. doi: 10.1371/journal.pone.0096182
Li, D., Niu, S., and Luo, Y. (2012). Global patterns of the dynamics of soil carbon and nitrogen stocks following afforestation: a meta-analysis. New Phytol. 195, 172-181.

Li, Q., Hu, Q., Zhang, C., Müller, W. E., Schröder, H. C., Li, Z., et al. (2015a). The effect of toxicity of heavy metals contained in tailing sands on the organic carbon metabolic activity of soil microorganisms from different land use types in the karst region. Environ. Earth Sci. 74, 6747-6756.

Li, Q., Wang, H., Jin, Z., Xiong, W., Wu, X., Zhang, Y., et al. (2015b). The carbon isotope fractionation in the atmosphere-soil-spring system associated with $\mathrm{CO}_{2}$-fixation bacteria at Yaji karst experimental site in Guilin. SW China. Environ. Earth Sci. 74, 5393-5401.

Li, Q., Liang, J. H., He, Y. Y., Hu, Q. J., and Yu, S. (2014). Effect of land use on soil enzyme activities at karst area in Nanchuan, Chongqing, southwest China. Plant Soil Environ. 60, 15-20.

Li, Q., Sun, H. L., and Wang, J. L. (2010). Hydrochemical sesponse of epikarst spring to rainfall: implications of nutrition element loss and groundwater pollution. Pol. J. Environ. Stud. 19, 441-448.

Li, Q., Yang, H., and Song, A. (2021). Comparative analysis of soil bacteria assemblages across land-use types in a given karst landscape in southwest China. Pol. J. Environ. Stud. (in press).

Liang, Y., Xiao, X., Nuccio, E. E., Yuan, M., Zhang, N., Xue, K., et al. (2020). Differentiation strategies of soil rare and abundant microbial taxa in response to changing climatic regimes. Environ. Microbiol. 22, $1327-1340$.

Loman, N. J., Constantinidou, C., Chan, J. Z., Halachev, M., Sergeant, M., Penn, C. W., et al. (2012). High-throughput bacterial genome sequencing: an embarrassment of choice, a world of opportunity. Nat. Rev. Microbiol. 10, 599-606.

Ma, B., Wang, H., Dsouza, M., Lou, J., He, Y., Dai, Z., et al. (2016). Geographical patterns of co-occurrence network topological features for soil microbiota at continental scale in eastern China. ISME J. 10, 1891-1901.

Ma, S., De Frenne, P., Boon, N., Brunet, J., Cousins, S. A. O., Decocq, G., et al. (2019). Plant species identity and soil characteristics determine rhizosphere soil bacteria community composition in European temperate forests. FEMS Microbiol. Ecol. 95: fiz063.

Marschner, H. (2011). Marschner's Mineral Nutrition of Higher Plants. Cambridge, MA: Academic press.

Marschner, P., Yang, C. H., Lieberei, R., and Crowley, D. E. (2001). Soil and plant specific effects on bacterial community composition in the rhizosphere. Soil Biol. Biohem. 33, 1437-1445.

McKinley, J. P., Zachara, J. M., Smith, S. C., and Liu, C. (2007). Cation exchange reactions controlling desorption of ${ }^{90} \mathrm{Sr}^{2+}$ from coarse-grained contaminated sediments at the Hanford site. Washington. Geochim. Cosmochim. Ac. 71, 305-325.

Morriën, E., Hannula, S. E., Snoek, L. B., Helmsing, N. R., Zweers, H., de Hollander, M., et al. (2017). Soil networks become more connected and take up more carbon as nature restoration progresses. Nat. Commun. 8:14349.

Neher, D. A. (1999). Soil community composition and ecosystem processes: comparing agricultural ecosystems with natural ecosystems. Agroforestry Syst. $45,159-185$.

Paul, E. A. (2007). Soil Microbiology, Ecology, and Biochemistry, 3rd Edn. Amsterdam: Academic.

Peng, X., Dai, Q., Ding, G., and Li, C. (2019). Role of underground leakage in soil, water and nutrient loss from a rock-mantled slope in the karst rocky desertification area. J. Hydrol. 578:124086.

Pickett, S. T. (1989). "Space-for-time substitution as an alternative to long-term studies," in Long-Term Studies in Ecology, ed G. E. Likens (New York, NY: Springer), 110-135.

Qin, J. H., Wu, Y. L., Yan, Y. J., and Zu, Z. F. (1996). Hercynian-Indosinian sedimentary-tectonic evolution of the Nanpanjiang Basin. Acta Geol. Sin. 70, 99-107.

Richardson, A. E., and Simpson, R. J. (2011). Soil microorganisms mediating phosphorus availability update on microbial phosphorus. Plant Physiol. 156, 989-996.

Rowley, M. C., Grand, S., and Verrecchia, ÉP. (2018). Calcium-mediated stabilisation of soil organic carbon. Biogeochemistry 137, 27-49.

Sangwan, P., Chen, X., Hugenholtz, P., and Janssen, P. H. (2004). Chthoniobacter flavus gen. nov., sp. nov., the first pureculture representative of subdivision 
two, Spartobacteria classis nov., of the phylum Verrucomicrobia. Appl. Environ. Microbiol. 70, 5875-5881.

Schmidt, R., Ulanova, D., Wick, L. Y., Bode, H. B., and Garbeva, P. (2019). Microbe-driven chemical ecology: past, present and future. ISME J. 13, 2656-2663.

Shao, P., Liang, C., Lynch, L., Xie, H., and Bao, X. (2019). Reforestation accelerates soil organic carbon accumulation: evidence from microbial biomarkers. Soil Biol. Biohem. 131, 182-190.

Shen, C., Ge, Y., Yang, T., and Chu, H. (2017). Verrucomicrobial elevational distribution was strongly influenced by soil $\mathrm{pH}$ and carbon/nitrogen ratio. J. Soils Sediment 17, 2449-2456.

Swenson, W., Wilson, D. S., and Elias, R. (2000). Artificial ecosystem selection. Proc. Natl. Acad. Sci. U.S.A. 97, 9110-9114.

Tamaki, H., Wright, C. L., Li, X., Lin, Q., Hwang, C., Wang, S., et al. (2011). Analysis of $16 \mathrm{~S}$ rRNA amplicon sequencing options on the Roche/454 next-generation titanium sequencing platform. PLoS One 6:e25263. doi: 10.1371/journal.pone. 0025263

Tenenhaus, M., Vinzi, V. E., Chatelin, Y. M., and Lauro, C. (2005). PLS path modeling. Comput. Stat. Data Anal 48, 159-205.

Tian, H., Chen, G., Zhang, C., Melillo, J. M., and Hall, C. A. (2010). Pattern and variation of $\mathrm{C}: \mathrm{N}$ : $\mathrm{P}$ ratios in China's soils: a synthesis of observational data. Biogeochemistry 98, 139-151.

Tong, X., Brandt, M., Yue, Y., Horion, S., Wang, K., De Keersmaecker, W., et al. (2018). Increased vegetation growth and carbon stock in China karst via ecological engineering. Nat. Sustain. 1, 44-50.

Van der Heijden, M. G., Bardgett, R. D., and Van Straalen, N. M. (2008). The unseen majority: soil microbes as drivers of plant diversity and productivity in terrestrial ecosystems. Ecol. Lett. 11, 296-310.

Wagg, C., Schlaeppi, K., Banerjee, S., Kuramae, E. E., and van der Heijden, M. G. (2019). Fungal-bacterial diversity and microbiome complexity predict ecosystem functioning. Nat. Commun. 10, 1-10.

Walker, T. W., and Adams, A. F. R. (1958). Studies on Soil Organic Matter: I. influence of phosphorus content of parent materials on accumulations of carbon, nitrogen, sulfur, and organic phosphorus in grassland soils. Soil Sci. 85, 307-318.

Wang, T., Flint, S., and Palmer, J. (2019). Magnesium and calcium ions: roles in bacterial cell attachment and biofilm structure maturation. Biofouling 35, 959-974.

Wogan, G. O., and Wang, I. J. (2018). The value of space-for-time substitution for studying fine-scale microevolutionary processes. Ecography 41, 1456-1468.
Xue, L., Ren, H., Brodribb, T. J., Wang, J., Yao, X., and Li, S. (2020). Long term effects of management practice intensification on soil microbial community structure and co-occurrence network in a non-timber plantation. Forest Ecol. Manag. 459:117805.

Xue, L., Ren, H., Li, S., Leng, X., and Yao, X. (2017). Soil bacterial community structure and co-occurrence pattern during vegetation restoration in karst rocky desertification area. Front. Microbiol. 8:2377. doi: 10.3389/fmicb.2017. 02377

Yuan, D. X. (1997). Rock desertification in the subtropical karst of south China. Z. Geomorphol. 108, 81-90.

Yuan, D. X. (2001). On the karst ecosystem. Acta Geol. Sin. 75, 336-338.

Yuan, Y., Li, Y., Mou, Z., Kuang, L., Wu, W., Zhang, J., et al. (2020). Phosphorus addition decreases microbial residual contribution to soil organic carbon pool in a tropical coastal forest. Global Change Biol. 27, 454-466. doi: 10.1111/gcb. 15407

Zhang, L., Cheng, Y., Gao, G., and Jiang, J. (2019). Spatial-temporal variation of bacterial communities in sediments in Lake Chaohu, a large, shallow eutrophic lake in China. Int. J. Env. Res. Pub. He. 16:3966.

Zhao, L. L., Leiy, Y. J., Chen, J. S., Zhu, S. R., Zhou, J. H., Tang, F. L., et al. (2019). Evolution process and comprehensive control of rocky desertification in Honghe state, Yunnan Province. Carsol. Sin. 5, 704-712.

Zhong, Z., Zhang, X., Wang, X., Fu, S., Wu, S., Lu, X., et al. (2020). Soil bacteria and fungi respond differently to plant diversity and plant family composition during the secondary succession of abandoned farmland on the Loess Plateau. China. Plant Soil 448, 183-200.

Zuo, X., Zhang, J., Lv, P., Zhou, X., Li, Y., Luo, Y., et al. (2016). Plant functional diversity mediates the effects of vegetation and soil properties on communitylevel plant nitrogen use in the restoration of semiarid sandy grassland. Ecol. Indic. 64, 272-280.

Conflict of Interest: The authors declare that the research was conducted in the absence of any commercial or financial relationships that could be construed as a potential conflict of interest.

Copyright (C) $2021 \mathrm{Li}$, Song, Yang and Müller. This is an open-access article distributed under the terms of the Creative Commons Attribution License (CC BY). The use, distribution or reproduction in other forums is permitted, provided the original author(s) and the copyright owner(s) are credited and that the original publication in this journal is cited, in accordance with accepted academic practice. No use, distribution or reproduction is permitted which does not comply with these terms. 